\title{
Seroprevalance of Helicobacter pylori in undernourished children: A hospital based study
}

\author{
Malik $\mathbf{S}^{1}$, Sharma $\mathbf{S}^{2}$, Dwivedi $\mathbf{R}^{3}$ \\ ${ }^{1}$ Dr Shikha Malik, Associate Professor, Department of Pediatrics, ${ }^{2}$ Dr Shweta Sharma, Assistant Professor, Department \\ of Pediatrics, ${ }^{3}$ Dr Rashmi Dwivedi, Professor \& Head. All are affiliated with Gandhi Medical College Bhopal MP India.
}

Address for Correspondence: Shikha Malik Associate Professor, F1 Doctors Quarter, Hamidia Hospital Campus, Bhopal, MP, India, E-mail id:gohiyapoorva@gmail .com

\begin{abstract}
Introduction: Helicobacter pylori is a gram negative, spiral flagellated bacillus that persistently colonizes the human stomach. H.pylori incidence in most of the developing countries including India is around 80\% and most of the infection is acquired by 10 years of age. In children it is associated with anaemia and undernutrition. We have taken up this study to find out its seroprevalance in undernourished children aged 6-12 years admitted in the hospital for various reasons.Material and Methods: This is a cross sectional study done over a period of one year in the pediatric department of a teaching hospital. After ethical committee clearance and parental consent, data was collected in a pretested proforma and serology was done for Ig $\mathrm{G}$ antibodies against H.pylori.(ELISA) in which a titre of $>12 \mathrm{micrograms} / \mathrm{ml}$ was considered positive.Results:We studied 60 children who fulfilled our inclusion criteria. The male to female ratio was comparable in the different age groups,with total29 males and 31 females.63.3\% of the children tested positive for antibodies against H.pylori. The seropositive children had significantly high tendencyof having symptoms of H.pylori infection. The relation between H.pylori seropositivity and low BMI was significant $(\mathrm{p}<0.005) .72 .7 \%$ of children who regularly consumed raw vegetables were seropositive but this association was not statistiticallysignificant.Low SES and increased overcrowding indexstatus was significantly associated with seropositivity.LowHb as per age and sex and low PCV were associated with seropositivity.Conclusion:Our study showed seroprevalance of H.pylori to be $63.3 \%$ in undernourished children. LowSES, overcrowding,open field defecation were significantly associated with $\mathrm{H}$ pylori infection. Low BMI, anemia and low PCV werestrongly associated with H.pylori seropositivity. Thus we conclude that H.pylori contributes to morbidity of already undernourished children therefore $\mathrm{H}$ pylori eradication regimen should be considered in undernourished children with suggestive symptoms.
\end{abstract}

Key Words: Overcrowding, Seropositivity, Anaemia, Low SES

\section{Introduction}

The acidic environment of stomach is incompatible with growth of most of the micro organisms. Helicobacter pylori is a gram-negative flagellate bacteria which is highly prevalent in developing countries. Its ubiquitous and infects more than half of global population [1]. H pylori when initially isolated was implicated in active and chronic gastritis, peptic ulcer disease and adenocarcinoma [2]. Over the years with increasing expertise in diagnosing causal organisms for different diseases, $\mathrm{H}$ pylori has been found to be causally related to recurrent abdominal pain, gastric mucosa associated lymphoid tissue

Manuscript received: $04^{\text {th }}$ Feb 2016

Reviewed: $12^{\text {th }}$ Feb 2016

Author Corrected; $18^{\text {th }}$ Feb 2016

Accepted for Publication: 26 ${ }^{\text {th }}$ Feb 2016 lymphoma, gastro esophageal reflux disease, obesity growth retardation and more recently extra gastric diseases like glaucoma, coronary heart disease and idiopathic thrombocytopenic purpura $[3,4]$.

H.pylori infection is acquired early in life and persists into adulthood[2].Mode of transmission is feco -oral or oro-oral. There are lots of adult studies on role of H.pylori as a causative agent of different diseases. Prevalence of $\mathrm{H}$. pylori is more in the developing countries than the developed nations. Up to $80 \%$ children in the developing world are infected under the age of 10 years. The prevalence of infection in India is 
$22 \%, 56 \%$ and $87 \%$ in $0-4,5-9$ and $10-19$ yearsage group respectively [5]. The diagnostic potential of direct microscopy, culture, rapidUrease test (RUT) of endoscopic antral biopsy tissues, urea breathtest and enzyme-linked immunosorbent assay (ELISA) ofantiHelicobacter pylori antibody in serum for the detection ofH. pylorihas been demonstrated [6]. We have taken up this study to find out the sero prevalence of H.pylori in the undernourished children belonging to 6-12 years age group who were admitted due to various reasons.

\section{Materials and Methods}

Study Design: Prospective cross sectional study.

Study Population: Undernourished children in age group 6-12 years admitted for various etiologies in department of pediatrics of a teaching hospital.

Study Period 1 year.

\section{Inclusion Criteria:}

- Undernourished children $\left(\mathrm{BMI}<5^{\text {th }}\right.$ centile as per WHO charts. [7]

- Age group 6-12 years.

- Children whose parents gave consent to participate in study along with blood sample collection for serum IgG antibody (against H.pylori) assessment.

\section{Exclusion criteria:}

- Children with $\mathrm{BMI}>5^{\text {th }}$ centile.

- Children with comorbities like HIV infection, immuncompromised state, on long-term steroids, taking antibiotics for $>7$ days.

- Children whose parents did not give consent for sample collection for serum IgG assessment.

Institutional ethical committee approved the study. Serum collection was done at the hospital and samples were sent to Religare laboratory for serum IgG antibodies against H.pylori. IgGantibodytiters of $>12 \mathrm{micrograms} / \mathrm{ml}$ were considered as positive. This is $77.3-78 \%$ sensitive and $91-93 \%$ specific [8].

A pretested proforma was used to collect the data of study population. The socio epidemiological factors, anthropometry, history of symptomssuggestive of $\mathrm{H}$ pylori infection were recorded. Complete blood picture and peripheral smear of all the subjects were sent for lab assessment.Data was processed using Microsoft Excel and SPSS 18 version. $\mathrm{P}$ value $<0.05$ was considered significant. Chi Square test and student $\mathrm{T}$ test were applied as test of significance.

\section{Results}

We studied 60 undernourished children who fulfilled the inclusion criteria. There were 29 males and 31 females (Table 1 )and $53.3 \%$ of children were in 8-10 years age group.

Table 1: Age distribution of Seronegative and seropositive children

\begin{tabular}{|c|c|c|c|}
\hline Age in Years & Sero negative & Seropositive & Total \\
\hline 6 & 4 & 1 & 5 \\
\hline $7-8$ & 11 & 12 & 32 \\
\hline $9-10$ & 7 & 25 & $\mathbf{6 0}$ \\
\hline Total & $\mathbf{2 2}$ & $\mathbf{3 8}$ \\
\hline
\end{tabular}

Table- 2: Anthropometry and its correlation with $\mathrm{H}$ pylori titers

\begin{tabular}{|l|c|c|c|c|c|}
\hline \multirow{3}{*}{ weight } & $\begin{array}{c}\text { Group } \\
\text { Ig G Titres }\end{array}$ & N & Mean weight & Std Deviation & Std Error of mean \\
\cline { 2 - 6 } & $<12$ & 22 & 18.568 & 2.44 & 0.52 \\
\hline \multirow{3}{*}{ height } & $>12$ & 38 & 18.249 & 2.17 & 0.35 \\
\cline { 2 - 6 } & $>12$ & 22 & 120.00 & 7.20 & 1.53 \\
\hline \multirow{2}{*}{ BMI } & $>12$ & 38 & 123.19 & 6.79 & 0.1 \\
\cline { 2 - 6 } & $>12$ & 22 & 12.86 & 0.51 & 0.07 \\
\hline
\end{tabular}


Table 3: Socioeconomic Status (SES) and Hpylori titre, Decreasing SES is significantly associated with seropositivity $(\mathbf{p}<\mathbf{0 . 0 5})$.

\begin{tabular}{|c|c|c|c|}
\hline SES & Seronegative & Seropositive & Total \\
\hline 1 & $3(100 \%)$ & 0 & 3 \\
\hline 2 & $9(69.2 \%)$ & $4(30.8 \%)$ & 21 \\
\hline 3 & $9(42.9 \%)$ & $12(57.1 \%)$ & 16 \\
\hline 4 & $1(6.3 \%)$ & $15(93.8 \%)$ & 7 \\
\hline 5 & 0 & $7(100 \%)$ & 60 \\
\hline & 22 & 38 & \\
\hline
\end{tabular}

Table 4: Hematological Parameters

\begin{tabular}{|l|c|c|c|c|}
\hline \multirow{4}{*}{ HEMOGLOBIN } & $\begin{array}{c}\text { Group } \\
\text { AsperIgGtitres }\end{array}$ & N & MEAN & STD. Deviation \\
\cline { 2 - 5 } & $<12$ & 22 & 11.150 & 1.5108 \\
\hline \multirow{3}{*}{ PCV } & $>12$ & 38 & 9.261 & 1.3114 \\
\cline { 2 - 5 } & $<12$ & 22 & 33.42 & 4.703 \\
\hline \multirow{3}{*}{ MCV } & $>12$ & 38 & 27.27 & 4.519 \\
\cline { 2 - 5 } & $>12$ & 22 & 70.486 & 2.5100 \\
\hline \multirow{3}{*}{ PLT } & $>12$ & 38 & 81.826 & .25302 \\
\hline \multirow{2}{*}{ RDW } & $>12$ & 22 & 1.9900 & 032890 \\
\cline { 2 - 5 } & $>12$ & 38 & 1.55553 & 2.3011 \\
\hline
\end{tabular}

The sero- positivity of $\mathrm{H}$ pylori was $63.3 \%$. $65.7 \%$ of sero -positive children were of $8-10$ years and $55.3 \%$ of positive children were females though this difference was not statistically significant.71\% of sero -positive children had gastrointestinal symptoms suggestive of $\mathrm{H}$ pylori infection as opposed to $7 \%$ in the sero -negative group. This difference was statistically significant with a $\mathrm{p}$ value $=0.003$. The mean BMI of seropositive children was 11.99 and of seronegative was 12.868 , this difference was statistically significantwith $\mathrm{p}<0.005$ (Table2). $72 \%$ of children who consumed raw vegetables regularly i.e. for 5 days in a week, were sero-positive.We used Kuppuswamy classification to define socioeconomic status (SES) (Table 3) and 100\% of children in SES 1 were sero negative whereas all were positive in SES 5, this difference was statistically significant. Mean overcrowding index of seropositive children was 2.7 as opposed to 1.6 of sero negative children, and the difference was statistically significant. Peripheral smear (Table 4) showed microcytic picture in $84 \%$ of seropositive children. Mean hemoglobin in sero-positive children was 9.2 whereas it was 11.15 in sero negative children. Mean red cell distribution width (RDW) was 22.9 in seropositive children and 19.2 in sero negative children $\mathrm{p}=0.003$.

\section{Discussion}

Our study on undernourished children $\left(\mathrm{BMI}<5^{\text {th }}\right.$ percentile) had shown $63.3 \%$ sero-positivity of $\mathrm{H}$. pylori in 6-10 years old children. Our results are comparable to other Indian studies $[9,10]$. Studies focused on asymptomatic children $[11,12]$ had shown sero-positivity between $23 \%-38 \%$. The sero-positivity in other developing countries is strikingly low $[13,14]$. As our study was done on undernourished hospitalized children, we had a high sero positivity which suggests that undernourished children should be evaluated for $\mathrm{H}$ pylori infection. H pylori sero-positivity had no sex difference in our study which is in accordance to other studies $[15,16,17]$.

Upper gastrointestinal symptoms, recurrent abdominal pain, dyspepsia all are said to be associated with H.pylori. Thisassumption has been supported by some studies done in developing countries 
$[18,19,20,21,22]$.Our study has also found statistically significant $(\mathrm{p}=0.003)$ association of symptoms of upper GI discomfort, dyspepsia and recurrent abdominal pain to be associated with $\mathrm{H}$ pylori sero-positivity. This observation should be considered in management of undernourished children with recurrent abdominal pain. The mean BMI of seropositive children was 11.99, which is less than 5 th centile, as well as significantly $(\mathrm{p}<0.005)$ low as compared to seronegative children. This observation suggests that H.pylori infection further compromises the already undernourished state of children. Therefore undernourished children management guidelines should alsoincorporate eradication of $\mathrm{H}$ pylori from stomach. The proportion of undernourished children belonging to lower socioeconomic status was sero-positive for $\mathrm{H}$ pylori whereas upper class children even when undernourished were seronegative. This association of socioeconomic status with sero-positivity is significant, which is corroborated in other studies done in developing countries[23,15]. Our studyfound significant relation of overcrowding with $\mathrm{H}$ pylori sero-positivity. The mean over crowding index was 2.7 in seropositive children. This relation of overcrowding with seroprevalance is significant as our study had undernourished children only.The factors, which contribute to prevalence of undernourishment, were present in both sero-positive and sero-negative group therefore the association of overcrowding with $\mathrm{H}$ pylori sero-positivity cant be associated with malnutrition only.Study from in Bangladesh [21] compared malnourished and nonmalnourished children have concluded that factors contributing to malnourishment are also associated with H. pylori seroprevalance. Hematological parameters, which we studied, were hemoglobin levels, RDW and peripheral smear. The mean Hemoglobin was significantly less in undernourished children who were seropositive as compared to seronegative children. The association of anemia with $\mathrm{H}$ pylori has been well established in various studies and is attributed to, malabsorption of iron because of increase in gastric $\mathrm{pH}$ and interference in ascorbic acid secretion [24].

\section{Conclusion}

We conclude that $\mathrm{H}$ pylori infection in already undernourished children further compromises their nutritional status and hematological parameters. As ours is a hospital based study the results can not be extrapolated for community but this can help in planning larger community based studies so as to make policy which will incorporate the regimen for $\mathrm{H}$ pylori eradication in the management of undernourished children who present with gastrointestinal symptoms.

\section{Funding: Nill, Conflict of Interest: None Permission of IRB: Yes}

\section{References}

1. Beckwith CS, McGee DJ, MobleyHLand, RileyLK.Cloning expression and catalytic activity of Helicobacter hepaticus urease. Infect Immune.2001; 69:5914-5920.

2. Johannes GK, van Valiet AHM and Kuipers EJ. Pathogenesis of Helicobacter pylori infection. Clinical Microbiol Rev. 2006 ;19(3): 449-490.

3. Soylu OB, Ozturk Y. Helicobacter pylori infection: effect on malnutrition and growth failure in dyspeptic children. Eur J Pediatr. 2008 May;167(5):557-62. Epub 2007 Jul 6

4. Suzuki H, Franceschi F, NishizawaT, Gasbarrini A .Extragastric manifestationof Helicobacter pylori. Helicobacter.2011;16Suppl 1:65-69.

5. Jagdish C Das and Nibedita Paul. Epidemiology and pathophysiology of helicobacter pyloriinfection in children.Indian J of Pediatrics.2007; 74(3): 287-290.

6. Kim JH, Kim JY, Kim NY, Kim SW et al .Helicobacter pylori infection ,seroepidemiology diagnosis and treatment. J GastroenterolHepatol. 2001;16: 969-975.

7.http://www.who.int/childgrowth/standards/en/.

8. Yelda A Leal,Laura L Flores,Laura B. Garcia Gortes.Antibody-Based Detection Tests for the Diagnosis of Helicobacter pylori Infection in Children: A Meta-AnalysisPLoS ONE 3(11): e3751. doi: 10.1371/journal.pone.0003751.

9. Gill HH, Majumdaar P, ShankaranK, Desai HG. Age related prevalence of Helicobacter pylori antibodies in Indian subjects .Indian J of Gastroenterology.1994;13:92-99.

10. Poddar U, Thapa BR. Helicobacter pylori infection in children. Indian Pediatrics.2000;37: 275-283.

11. Misra V, Misra SP, Diwedi M, Singh PA. Point prevalence of peptic ulcer and gastric histology in healthy Indians with Helicobacter pylori infection. Am J Gastroeterol 1997; 92: 1487-1489. 
12. Jais M, Barua S. Seroprevalence of anti Helicobacter pylori IgG/IgA in asymptomatic population from Delhi. J Commun Dis 2004; 36: 132135.

13. Fraser AG, Scragg R, Metcalf $P$, McCullough S, Yeates NJ. Prevalence of Helicobacter pylori infection in different ethnic groups in New Zealand children and adults. Aust N Z J Med 1996;26: 646-651.

14. Rothenbacher D, Bode G, Berg G, Gommel R, Gonser T, Adler G, Brenner H. Prevalence and determinants of Helicobacter pylori infection in preschool children: a population-based study from Germany. Int J Epidemiol 1998;27: 135-141.

15. Bardhan PK. Epidemiological features of Helicobacter pylori infection in developing countries.Clin Infect Dis 1997;25: 973-978.

16. Smith SI, Oyedeji KS, Opere B, I walokun BA, Omonigbehin EA. The effects of some Nigerian local herbs on Helicobacter pylori. Afr J ClinExpMicrobiol 2003; 4: 29-35.

17. Chong SK, Lou Q, Zollinger TW, Rabinowitz S, Jibaly R, Tolia V, Elitsur Y, Gold BD, Rosenberg A, Johnson A, Elkayam O, Rosenthal P, Gilger M, Li BU, Peacock JS. The seroprevalence of Helicobacter pylori in a referral population of children in the United States. Am J Gastroenterol 2003;98: 2162-2168.

18. Singh M, Prasad KN, Yachha SK, Saxena A, Krishnani N. Helicobacter pylori infection in children: prevalence, diagnosis and treatment outcome. Trans $\mathrm{R}$ Soc Trop Med Hyg 2005; 27: 227-233.

19. Biswal N, Ananthakrishnan N, Kate V, Srinivisan S, Nalini P, Mathai B. Helicobacter pylori and recurrent pain abdomen. Indian J Pediatr 2005; 72: 561-565.

20. Das BK, Kakkar S, Dixit VK, Kumar M, Nath G, Mishra OP. Helicobacter pylori infection and recurrent abdominal pain in children. J Trop Pediatr 2003; 49: 250-252.

21. Haque W, Ahsan CR, Nessa J and Yasmin M.Associationbetween malnutrition and other possible risk elements with theacquisition of $\mathrm{H}$. pylori infection among the children population in Bangladesh. Bang $\mathrm{J}$ Microbiol.2009; 26(1\&2): 9-14.

22. Idowu O Senbanjo1, KazeemA Oshikoya2, Olisamedua F Njokanma. Helicobacter pylori associated with breastfeeding, nutritional status and recurrent abdominal pain in healthy Nigerian children. Journal of Infect.Dev. Ctries.2014;8(4):448-453 doi:10.3855/jidc.3196.

23. MalatyHM, and Graham DY. Importance of childhood socioeconomic status on the currentprevalence of Helicobacter pylori infection. Gut.1994;35(6): 742-745.Gutv.35(6); 1994 JunPMC1374869.

24. Koike T, Ohara S, Sekine H, Iijima K, Abe Y, Kato K, Toyota T, Shimosegawa T. Helicobacter pylori infection preventserosive reflux oesophagitis by decreasing gastric acid secretion. Gut 2001; 49: 330334.

\section{How to cite this article?}

Malik S, Sharma S, Dwivedi R, Seroprevalance of Helicobacter pylori in undernourished children: A hospital based study : Iraq: Int J Pediatr Res 2016;3(3):151-155. doi:10.17511/ijpr.2016.i03.03. 